\title{
Appendix Neuroendocrine Tumor pT3 TNM Finding v8
}

National Cancer Institute

\section{Source}

National Cancer Institute. Appendix Neuroendocrine Tumor pT3 TNM Finding v8. NCI

Thesaurus. Code C135149.

Appendix neuroendocrine tumor measuring more than $4 \mathrm{~cm}$ or with subserosal invasion

or involvement of the mesoappendix. (from AJCC 8th Ed.) 